\title{
Effects of different plant growth regulators on in vitro callus induction in physic nut (Jatropha curcus L.)
}

\author{
Sunil Kumar ${ }^{1}$, Virendra Kumar ${ }^{2}$, Manoj Kumar Sharma ${ }^{1}$, Narendra Kumar ${ }^{3}$, Anil Kumar ${ }^{2}$, \\ Kushal Pal Singh Tomar ${ }^{2}$, Sarjeet Kumar Sharma ${ }^{4}$, Mukesh Kumar Singh ${ }^{4}$, R. S. Sengar ${ }^{1}$ \\ and Nidhi Jaiswal ${ }^{1}$ \\ ${ }^{1}$ Department of Agricultural Biotechnology, Sardar Vallabhbhai Patel University of Agriculture and Technology, \\ Meerut-250 110 (U.P.), INDIA \\ ${ }^{2}$ Department of Genetics and Plant Breeding, Sardar Vallabhbhai Patel University of Agriculture and Technology, \\ Meerut-250 110 (U.P.), INDIA \\ ${ }^{3}$ Department of Agronomy, Sardar Vallabhbhai Patel University of Agriculture and Technology, Meerut-250 110 \\ (U.P.), INDIA \\ ${ }^{4}$ Institute of Agricultural Sciences, Banaras Hindu University, Varanasi-221 005 (U.P.), INDIA \\ *Corresponding author. E-mail: kumarvirendra26@gmail.com
}

Received: September 8, 2014; Revised received: December 24, 2014; Accepted: February 12, 2015

\begin{abstract}
Jatropha (Jatropha curcas L.) is an oil bearing crop growing in tropical and subtropical parts of the world. The present study was undertaken to investigate the effects of different plant growth regulators on in vitro callus induction in physic nut (J. curcus). In the present study, it was observed that all the explants viz., leaf lamina, petioles, nodal segments and cotyledonary nodes showed good callus induction responses on various culture media thus tried. Leaf lamina and petioles showed $100.0 \%$ callus induction responses on different MS media supplemented with auxins and cytokinins alone or in combinations whereas, nodal segments and cotyledonary nodes showed maximum $89.6 \%$ and $83.9 \%$ callus induction respectively. The presence of $2,4-\mathrm{D}$ in culture media with auxins or cytokinins was essential for good callus growth. Among different explants tried, leaf lamina was the best responding explants and MS-13 media supplemented with $5 \times 10^{-6} \mathrm{M} \mathrm{NAA}$ and $10^{-5} \mathrm{M} 2$, 4-D is the best callusing and growth supporting medium. However, the regenerative competence of the callus tissues can differ depending on the type of explants used because certain types of plant tissues have more favorable regeneration responses than others. Callus induction rate from all explant types was highest than other reports. The results obtained in the present study would facilitate the high callus induction and regeneration responses in J. curcus for its improvement using biotechnological tools.
\end{abstract}

Keywords: Auxins, Callus, Jatropha, Plant regeneration, Tissue culture

\section{INTRODUCTION}

Jatropha (Jatropha curcas L., 2n=22), the biodiesel plant is also known as Physic nut, Purgative nut, Barbados nut, Ratanjot, Jamalghota, Kali Indoli, Sabudam, Sujotiya, Jangli arandi or Kalaranda, belongs to the family Euphorbiaceae. The genus Jatropha has 175 known species of the plants. Originating in the Caribbean, Jatropha was spread to Africa and Asia by Portuguese traders. Nowadays, it is cultivated in many parts of the tropics and subtropics as a valuable hedge crop and for traditional uses (Kumar and Sharma, 2008). The plants are drought-resistant succulent shrubs or trees, and are recognized as potential biofuel crop. J. curcas, J. integerrima and $J$. glandulifera are native to South America. Among the various Jatropha species, Jatropha curcas, J. glandulifera, J. gossypifolia, J. integerrima, J. multifida, J. nana, J. podagrica, and J. tanjorensis are widely cultivated, naturalized and distributed in India. The term
"Jatropha" is usually and commonly used to refer to the species $J$. curcas. Many of the family members have some ornamental use except $J$. curcas and $J$. glandulifera that are oil-yielding species. J. curcas is considered as a potential crop for local fuel production. At optimal conditions, about 5.0 tons/ha seed is produced per year. The hull and the kernel have a high oil content that can reach up to about $60 \%$ and which can be transformed into fuel through esterification (Li et al., 2007). The oil is high in octane value and can be used directly in diesel engines added to diesel fuel as an extender or transesterized to a biodiesel fuel. Due to the presence of several toxins including curcascine or curcin, phorbol esters, saponins, protease inhibitors and phytates, the seed or the oil cannot be used for human or animal consumption (Menezes et al., 2006). In contrast to the varieties used for oil production, some Mexican J. curcas accessions are edible. Jatropha is known for its use as purgative/laxative, and other medicinal 
uses. All parts of the plant, including seeds, leaves and bark, fresh or as a decoction, are used in traditional and folk medicine and veterinary purposes. The latex of Jatropha contains several alkaloids viz., Jatrophine, Jatropham and curcain with anti-cancer properties (Thomas et al., 2008). The roots are reported as an antidote for snake-bites. All parts of the plant show insecticidal properties e.g., against insect/pests like cotton bollworm, and on pests of pulses, potato and corn (Kaushik and Kumar, 2004). In addition, Jatropha oil is used in making soaps, candles, paints, lubricants and medicines (Sujatha and Mukta, 1996). J. curcas is becoming a commercial source of biodiesel production in several West-African (Senegal) and South-East African (Zambia, Tanzania, Namibia) countries, as well as in Asia (Philippines and especially in India) where state governments are actively promoting its commercialization. Energy experts claim that Jatropha oil is an environmentally safe, cost-effective renewable source of non-conventional energy, and a promising substitute for diesel, kerosene and other fuels (Abdulla et al., 2011). Because of the increased interest in the potential of Jatropha as an energy plant, more attention is given to methods that allow the mass production of elite material. The method most suitable for generating large numbers of plantlets is in vitro propagation. Hence the rapid growing list of reports on tissue culture analysis of $J$. curcas. Tissue culture studies were undertaken in different species of Jatropha. In recent past, some of the advances in establishing an efficient and reproducible system of in vitro regeneration of selected genotypes of Jatropha have been reported by various researchers (Sujatha and Mukta, 1996; Mujib et al., 1998; Kumari and Jaiwal, 1998; Sardana et al., 2000; Sahrawat and Chand, 2001; Ramasamy et al., 2005; Liu et al., 2006; Rajore and Batra, 2007; Shrivastava and Banerjee, 2008; Deore and Johnson, 2008; Thepsamran et al., 2008; Kumar and Reddy, 2010; Shamsiah et al., 2010; Sridhar and Naidu, 2011; Jose et al., 2012). All the above studies reported either callus mediated regeneration or direct shoot morphogenesis with or without interspersed callus from endosperm, hypocotyls, epicotyls, leaf, auxiliary nodes, shoot tips, endosperm and petioles. From the results presented by the authors, it has been observed that independent of the regeneration method and the source of the explants used, it is possible to achieve the multiplication of Jatropha in vitro. Callus culture is the source of variations in vitro that could be useful for improvement of Jatropha by obtaining desirable variants. For it rapid and efficient protocol is needed that describes the role of growth regulators on in vitro callus induction in a clear cut fashion thus save time and efforts. Therefore, the present study was undertaken to investigate the effects of different plant growth regulators on in vitro callus induction in physic nut (J. curcus L.).

\section{MATERIALS AND METHODS}

Plant materials: For the present study, the explants viz., leaf lamina, nodal segments, petioles and cotyledonary nodes were used as plant materials. The explants viz., leaf lamina, nodal segment and petioles were excised during the period of active growth from two year old healthy plants maintained at Sardar Vallabhbhai Patel University of Agriculture and Technology, Meerut (U.P.).whereas the cotyledonary nodes were excised from 10 days old seedlings of Jatropha curcus, whose seeds were collected from the plants maintained at Chaudhary Charan Singh Haryana Agriculture University, Hisar and Indira Gandhi Krishi Vishvidhyalaya Raipur, Chhatisgarh. The experimental work was carried out at the Department of Agriculture Biotechnology, College of Agriculture, Sardar Vallabhbhai Patel University of Agriculture and Technology, Meerut (U.P.) during 2010-11. All experiments were planned to investigate the effects of different plant growth regulators (Kinetin, 2, 4-D, IBA, NAA alone or in combination) on in vitro callus induction in J. curcus.

Culture media preparation: Success of a tissue culture protocol depends on the appropriate composition of the medium. Several basal formulations like-MS (Murashige and Skoog, 1962), $\mathrm{B}_{5}$ (Gamborg et al., 1968), SH (Schekar and Hildebrandt, 1972), etc. are now available but in the present study, MS basal media (Muarashige and Skoog, 1962) with or without plant growth regulators was used. Twenty different media having separate combinations of plant growth regulators were used to evaluate the effects on in vitro callus induction from different explant types (Table 1). The media were augmented with different concentrations and combinations of 6-furfurylaminopurine [Kinetin $(\mathrm{Kn})], 2$, 4diphenoxyaceticacid (2, 4-D), Indole-3-butyric acid (IBA) and $\alpha$-Naphthalene acetic acid (NAA) (Hi Media, Mumbai, India). For media preparation, calculated amount of aliquots were added from the stock solutions. Media were then fortified with $100 \mathrm{mg} / \mathrm{L}$ myo-inositol and 3.0\% sucrose (Hi-media, Mumbai, India). The final volume was made up with double distilled water. Unless mentioned, $\mathrm{pH}$ of all the media was adjusted to 5.8 using $1.0 \mathrm{~N} \mathrm{NaOH} / \mathrm{HCl}$ and then culture media were solidified using $0.8 \%$ agar (Bacteriological Grade, Hi media, India) prior to autoclaving. The media were then heated on hot plate for the agar to melt. Molten medium was later dispensed into sterile culture tubes $(25 \mathrm{~mm} \times 150 \mathrm{~mm})$ containing $15 \mathrm{~mL}$ media after thorough mixing. All culture tubes were capped with polypropylene caps. All the culture media were autoclaved for $20 \mathrm{~min}$ at $121^{\circ} \mathrm{C}$ temperature and $15 \mathrm{lb} / \mathrm{inch}^{2}$ pressure. After autoclaving, the culture vessels containing media were incubated in culture room for further use.

Preparation of explants and surface sterilization: For cotyledonary nodes, seeds of $J$. curcus were incubated on well-soaked sand in glass tray after removing their hard seed coat mechanically and kept in naturally lit pot house. After excision all the explants viz., leaf lamina, nodal segments, petioles and cotyledonary nodes were first washed with aqueous teepol solution $(1: 5 \mathrm{v} / \mathrm{v})$ for 
5 min and then rinsed in running tap water for 15-20 minutes. These explants were further surface sterilized with $0.1 \%$ Bavistin (BASF India Ltd) for $5 \mathrm{~min}, 70 \%$ ethanol for 30 second and $0.1 \% \mathrm{HgCl}_{2}$ for $5 \mathrm{~min}$, respectively, under the hood of laminar air flow. The traces of $\mathrm{HgCl}_{2}$ were removed by 3-4 washings with pre-sterilized double distilled water. After sterilization, these explants were inoculated in culture tubes containing MS basal medium amended with various concentrations of auxins or cytokinins alone or in combinations.

Culture conditions : All the experiments for in vitro studies were conducted under controlled light, relative humidity and temperature conditions. The temperature was maintained at $25 \pm 2^{\circ} \mathrm{C}$. Relative humidity was adjusted to $60-70 \%$. Light intensity having $35 \mu \mathrm{E} \mathrm{m}^{-2} \mathrm{sec}^{-1}$ irradiance levels was provided using fluorescent tubes and tungsten bulbs (Phillips, India) over a light and dark period of $16 \mathrm{hrs}$ and $8 \mathrm{hrs}$, respectively.

Statistical analysis: Data on percent callus induction after 20, 28 and 35 days of explant inoculation were recorded for all explants. For each treatment about six tubes of each medium were used. All the experiments were carried out in a complete randomized design maintained with three replicates and each experiment was repeated thrice. ANOVA was performed to test for differences in embryogenic callus induction from all explants. Significant means differences were also determined.

\section{RESULTS}

Callus induction in mostly, all the tested media was evident after 17 days of inoculation in all explants used for the present study. The callus was light green with a fragile texture. Following results were observed in the present study.

\section{A. Effects of different concentrations of NAA, IBA and 2, 4-D on in vitro callus induction}

Callus induction from leaf lamina: In the present study, it was observed that the percent callus induction increased with increase in the concentrations of auxins tested and days after inoculation (DAI) except for those on medium supplemented with IBA. Very little percentage of callus induction was evident in control medium (MS Basal or MS-1 media) which increased further with the supplementation of NAA or 2, 4-D, to the MS medium (Table- 2). All the explant types showed callus induction on tested media. Highest callus induction responses $(100.0 \%)$ from leaf lamina were reported on MS-4 and MS-8 media after 35 days of explant inoculation on media.

Callus induction from nodal segments: Callus induction in nodal segments on MS medium supplemented with different concentrations of NAA was more over the growth regulators free MS medium (Table- 2). MS medium amended with IBA, NAA and 2, 4-D induced good callusing responses in all tested explant types. Like leaf lamina and petioles, nodal segments and cotyledonary nodes did not resulted in $100 \%$ callus induction (Table- 2). Best callus responses $(60.5 \%)$ were reported on MS-8 media after 35 days of explants inoculation on media.

Callus induction from petiole: Callus induction from petiole explants on MS medium supplemented with NAA and 2, 4-D was more as compared to control and IBA and the best response in terms of callus induction efficiency was evident on MS-4 and MS-8 media (Table 2). Like leaf lamina and nodal segments, petiole segments responded very well to IBA (MS5, MS6 and MS7). Similarly, MS8 media produced callus growth as to MS-4 media.

Callus induction from cotyledonary nodes: Addition of NAA to the MS medium improved callus induction from the cotyledonary nodes (Table 2). NAA gave best callus response $(31.8 \%)$ when used at $10^{-5} \mathrm{M}$ concentration (MS-4). Best callus responses from cotyledonary nodes were reported on MS-8 media.

B. Effects of different concentrations of NAA and IBA in combinations with BAP, KIN and 2, 4-D on callus induction

Callus induction from leaf lamina: Addition of NAA, IBA, KIN and 2, 4-D in different combinations induced $100 \%$ callusing from leaf lamina and petiole explants (Table- 2). In case of leaf lamina $100.0 \%$ callus induction was reported on MS-12, MS-13 and MS-16. Among tested media combinations, MS-13 showed highest callus induction $(89.6 \%)$ from nodal segments after 35 days of explants inoculation. According to the results, it was observed that the addition of NAA and IBA was essential to induce $100.0 \%$ callus from leaf lamina.

Callus induction from nodal segments: Addition of NAA, IBA, KIN and 2, 4-D in different combinations exhibited varied responses in terms of callus induction from nodal segments (Table 2). Highest callus induction $(89.6 \%)$ from nodal segments was shown on MS-13 media followed by MS-12 (83.4\%) and MS-16 $(73.9 \%)$. Like as leaf lamina, the addition of NAA and IBA was also essential for callus induction from nodal segments.

Callus induction from petioles: Addition of NAA, IBA, KIN and 2, 4-D in different combinations also induced calluses from petioles on MS medium. In case of petioles, MS-12, MS-13 and MS-16 were also suitable media for $100.0 \%$ callus induction (Table- 2). The combinations of NAA and IBA with 2, 4-D also suggested the role of these three auxins in callus induction from petioles. Like leaf lamina, petioles also showed cent percent callus induction within 20-35 days of explant inoculation on MS media fortified with NAA, IBA and 2, 4-D. Effects of growth regulators on callus induction from different explants are depicted in fig. 1.

Callus induction from cotyledonary nodes: Addition of NAA, IBA, KIN and 2, 4-D in different combinations also induced calluses from cotyledonary nodes also on MS medium. In case of cotyledonary nodes, MS-13 showed highest callus induction responses followed by MS-12 and MS-16 culture media (Table- 2). As in case of petioles, the combinations of NAA and IBA with 2 , 
Table 1. Twenty different combinations of MS media used in the present study.

\begin{tabular}{|c|c|}
\hline Media code & Media Composition \\
\hline MS-1 & MS Basal \\
\hline MS-2 & $\mathrm{MS}+10^{-6} \mathrm{M} \mathrm{NAA}$ \\
\hline MS-3 & $\mathrm{MS}+5 \times 10^{-6} \mathrm{M}$ NAA \\
\hline MS-4 & $\mathrm{MS}+10^{-5} \mathrm{M} \mathrm{NAA}$ \\
\hline MS-5 & $\mathrm{MS}+10^{-6} \mathrm{M}$ IBA \\
\hline MS-6 & $\mathrm{MS}+5 \times 10^{-6} \mathrm{M}$ IBA \\
\hline MS-7 & $\mathrm{MS}+10^{-5} \mathrm{M}$ IBA \\
\hline MS-8 & $\mathrm{MS}+5 \times 10^{-6} \mathrm{M} 2,4-\mathrm{D}$ \\
\hline MS-9 & $\mathrm{MS}+5 \times 10^{-6} \mathrm{M} \mathrm{NAA}+10^{-6} \mathrm{M} \mathrm{KIN}$ \\
\hline MS-10 & $\mathrm{MS}+5 \times 10^{-6} \mathrm{M} \mathrm{NAA}+5 \times 10^{-6} \mathrm{M} \mathrm{KIN}$ \\
\hline MS-11 & $\mathrm{MS}+5 \times 10^{-6} \mathrm{M} \mathrm{NAA}+10^{-5} \mathrm{M} \mathrm{KIN}$ \\
\hline MS-12 & $\mathrm{MS}+5 \times 10^{-6} \mathrm{M}$ NAA $+5 \times 10^{-6} \mathrm{M} 2,4-\mathrm{D}$ \\
\hline MS-13 & $\mathrm{MS}+5 \times 10^{-6} \mathrm{M} \mathrm{NAA}+10^{-5} \mathrm{M} 2,4-\mathrm{D}$ \\
\hline MS-14 & $\mathrm{MS}+5 \times 10^{-6} \mathrm{M} \mathrm{IBA}+10^{-6} \mathrm{M} 2,4-\mathrm{D}$ \\
\hline MS-15 & $\mathrm{MS}+4.9 \times 10^{-6} \mathrm{M} \mathrm{IBA}+2.2 \times 10^{-6} \mathrm{M} 2,4-\mathrm{D}$ \\
\hline MS-16 & $\mathrm{MS}+4.9 \times 10^{-6} \mathrm{M} \mathrm{IBA}+4.4 \times 10^{-6} \mathrm{M} 2,4-\mathrm{D}$ \\
\hline MS-17 & $\mathrm{MS}+5 \times 10^{-6} \mathrm{M} \mathrm{IBA}+10^{-5} \mathrm{M} \mathrm{BAP}$ \\
\hline MS-18 & $\mathrm{MS}+5 \times 10^{-6} \mathrm{M} 2,4-\mathrm{D}+5 \times 10^{-6} \mathrm{M} \mathrm{KIN}$ \\
\hline MS-19 & $\mathrm{MS}+5 \times 10^{-6} \mathrm{M} 2,4-\mathrm{D}+5 \times 10^{-6} \mathrm{M} \mathrm{KIN}+2.5 \times 10^{-6} \mathrm{M}$ NAA \\
\hline MS-20 & $\mathrm{MS}+5 \times 10^{-6} \mathrm{M} 2,4-\mathrm{D}+5 \times 10^{-6} \mathrm{M} \mathrm{KIN}+2.5 \times 10^{-6} \mathrm{M} \mathrm{IBA}$ \\
\hline
\end{tabular}

4-D also suggested the role of these three auxins in callus induction from cotyledonary nodes.

C. Effects of the same concentrations of 2, 4-D and KIN alone or in combination with NAA or IBA on percent callus induction

Callus induction from leaf lamina: Supplementation of MS medium with $5 \times 10^{-6} \mathrm{M}$ each 2 , 4-D and KIN increased callus induction percentage marginally but did not affect callus growth significantly from leaf lamina from all the tested explants in this study. MS medium supplemented with combinations of 2, 4-D, $5 \times 10^{-6} \mathrm{M}+\mathrm{KIN} 5 \times 10^{-6} \mathrm{M}$ with $2.5 \times 10^{-6} \mathrm{M}$ NAA (MS-19) or $2.5 \times 10^{-6} \mathrm{M}$ IBA (MS-20) induced maximum $81.5 \%$ and $71.8 \%$ callus induction after 35 days of inoculation. Callus growth on the former medium has an edge over the growth on the latter medium (Table- 2).

Callus induction from nodal segments: All the tested combinations of 2, 4-D + KIN with NAA or IBA induced maximum $62.7 \%$ callusing (MS-19) and enhanced callus growth significantly over the control medium (Table- 2). Callus growth was the best also on MS medium supplemented with $5 \times 10^{-6} \mathrm{M} 2,4-\mathrm{D}+5 \times 10^{-6} \mathrm{M} \mathrm{KIN} \mathrm{+}$ $2.5 \times 10^{-6} \mathrm{M}$ NAA (MS-19) and MS+2, 4-D, $5 \times 10^{-6} \mathrm{M}+$ KIN, $5 \times 10^{-6} \mathrm{M}+\mathrm{IBA}, 2.5 \times 10^{-6} \mathrm{M}$ (MS-20), respectively. Callus induction from petioles: Addition of 2, 4-D, KIN and NAA in culture media induced calluses from petioles in vitro. In case of petioles, MS-19 media was suitable media for maximum $76.6 \%$ callus induction within 35 days of explant inoculation whereas, MS-20 showed only $66.7 \%$ callus induction (Table- 2 ). The combinations of auxins and cytokinins (2, 4-D, KIN and NAA) also proved their roles of in callus induction from petioles. Like leaf lamina, petioles also showed a good percentage of callus induction within 20-35 days of explant inoculation on MS media fortified with 2, 4-D,
NAA and Kinetin (KIN).

Callus induction from cotyledonary nodes: The presence of 2, 4-D, NAA and Kinetin in culture media was also essential to induce callus from cotyledonary nodes. Like as leaf lamina, petioles, the callus responses were about to more than half $(57.3 \%$ on MS-19) whereas, it was slightly lower than nodal segments. As in case of leaf lamina, petioles and nodal segments, MS-19 showed more responsibility in callus induction from cotyledonary nodes instead of MS-20.

\section{DISCUSSION}

In the present study, the effects of different plant growth regulators on in vitro callus induction in physic nut (J. curcus) were evaluated by employing leaf lamina, nodal segments, petioles (from two years old plants) and cotyledonary nodes (from 10 days old seedlings) as explants. A variety of tissues have been used for the induction of callus. Both the application of auxin as well as high cytokinin concentrations was effective. Fast growing, compact callus can be induced from MS medium, supplemented with various combinations of 2, 4-D, Kinetin, NAA and IBA. Vegetative plant parts especially leaves, nodes and shoot tips are desirable explants for in vitro cultures because plant regeneration from these explants would preserve the genetic identity of the parent genotype (Sridhar and Naidu, 2011). Callus induction is a prerequisite for large scale secondary metabolite production, adventitious improvement and for genetic engineering (Jose et al., 2012). The earlier studies reported that several types of explants of $J$. curcas responded very positively to these hormones with respect to induction of callus, shoots, roots, somatic embryos (Sardana et al., 2000). Callus induction in $J$. 
Sunil Kumar et al. / J. Appl. \& Nat. Sci. 7 (1) : 30 - 37 (2015)

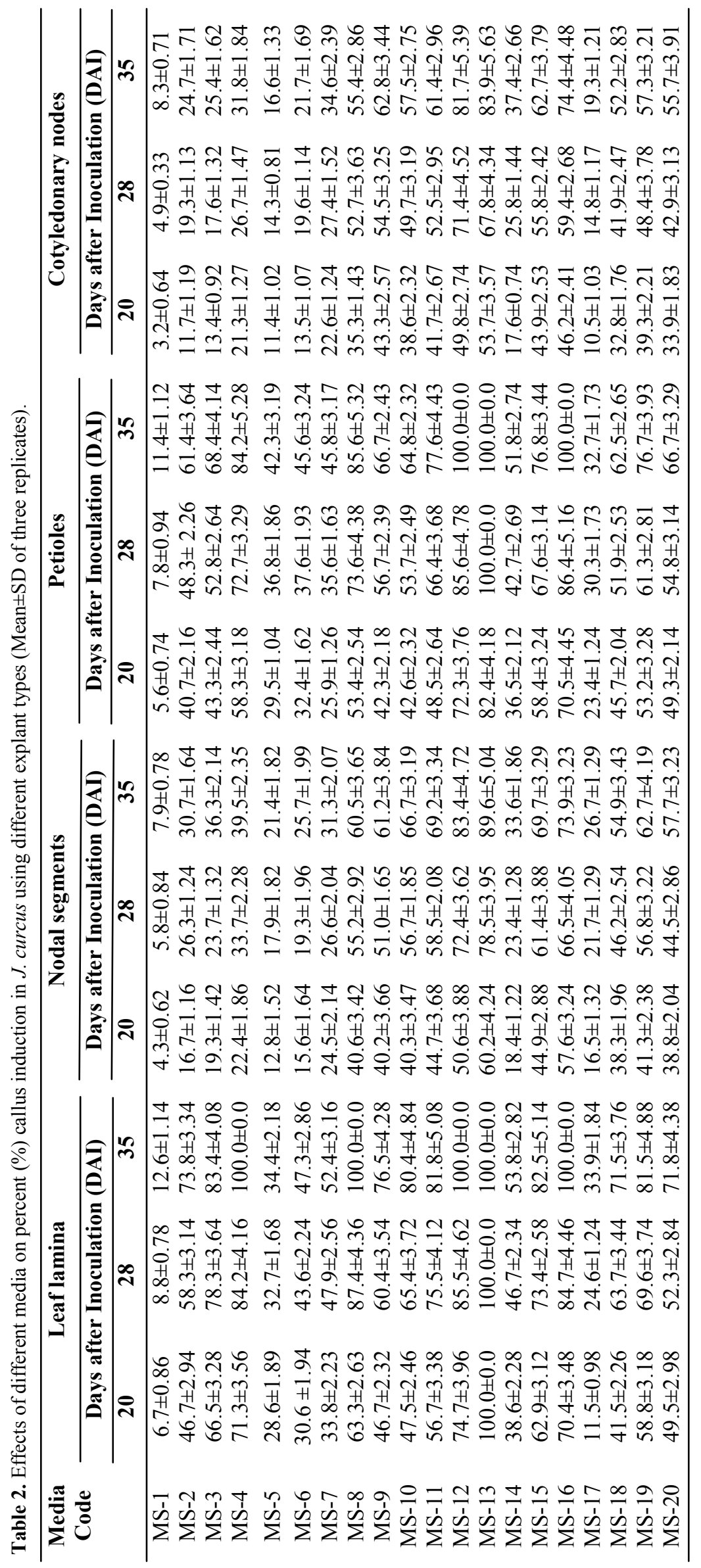



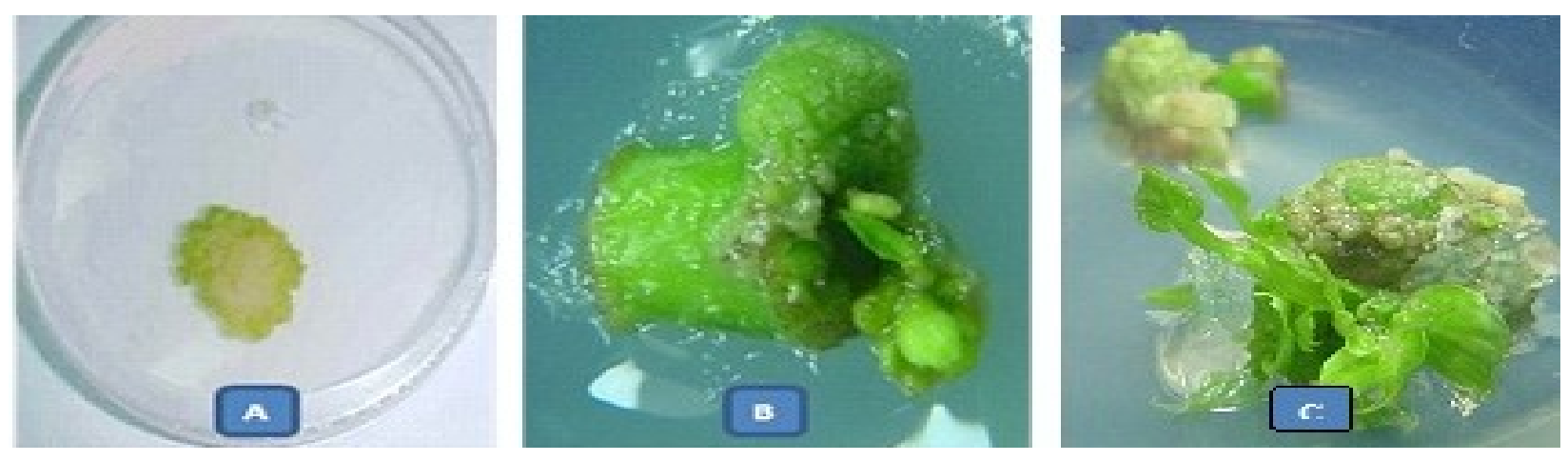

Fig. -1: In Vitro callus induction in J. curcus after 8 Weeks using different explants (A) from petiole on MS+2, 4-D, $5 \times 10^{-6} M$ (B) from nodal segment on $M S+N A A, 5 \times 10^{-6} M+K I N, 5 \times 10^{-6} M$ (C) from leaf lamina on $M S+I B A, 4.9 \times 10^{-6} M+2,4-D$, $4.4 \times 10^{-6} \mathrm{M}$. Also showing shoot regeneration from callus tissues.

curcus from petioles and leaf discs have also been reported earlier (Deore and Johnson, 2008; Shamsiah et al., 2010).

In the present study, it was observed that the source of the explants and cultures significantly influenced the callus induction responses. Trails on various media recipes revealed that callus was initiated within 17 days of inoculation in all explants except of two weeks incubation period has been reported for different explants of $J$. curcus on media supplemented with auxins, except IAA which failed to elicit any response in any of the explants (Sujatha and Mukta, 1996). Callus induction always preceded by swelling of the explant. According to the results observed in the current study, NAA $\left(10^{-5}\right.$ $\mathrm{M})$ and 2, 4-D $\left(5 \times 10^{-6} \mathrm{M}\right)$ alone showed $100.0 \%$ callus induction from leaf lamina explants in $J$. curcus whereas other explants types failed to induce callusing like as leaf lamina. In nodal explants NAA showed lower callus induction rate than 2, 4-D that provide provided maximum $60.5 \%$ callus induction. From cotyledonary nodes 2, 4-D was more suitable than MS basal media or media containing NAA and IBA. However, in the present study, it was observed that no one plant growth regulator failed to induce callusing from any of the tested explants. NAA concentrations above $10^{-6} \mathrm{M}$ and $5 \times 10^{-6} \mathrm{M} 2$, 4-D improved callus growth, the latter however, produced the best response in leaf lamina and petiole explants. BAP with auxins also showed callus induction in a little from all the explants tested in the current study. Sujatha and Mukta (1996) succeeded to induce callusing from cotyledonary nodes and hypocotyls by using Zeatin only; the response being very slow which was accompanied by necrosis. When leaf explants were used, high concentrations of BAP with NAA induced callus within 3-4 weeks (Rajore and Batra, 2007). Interestingly, NAA $\left(10^{-6}-10^{-5} \mathrm{M}\right)$ alone in MS media also induces callus from all the tested explants. This finding suggests that $J$. curcas is highly sensitive to auxin with respect to the stimulation of cell division rather than the induction of roots (Shrivastava and Banerjee, 2008). The replacement of NAA by IBA in combination with 2, 4-D also induced calluses in this study. It was also suggested by some earlier reports (Sujatha and Mukta, 1996; Deore and Johnson, 2008; Thepsamran et al., 2008). In these reports, however, IBA on its own was not sufficient to stimulate callus formation from leaf explants. 2, 4-D and Kinetin when used in combination with NAA and IBA separately also showed very good callus induction responses from leaf lamina and petioles whereas, in nodal segments 2, 4-D in combination with NAA was more effective than 2, 4-D with IBA. Both cytokinins (Kinetin) with auxins (NAA and IBA) also showed good callus induction and growth responses. Increasing concentrations of auxins in culture media significantly increased callus induction and growth responses in all the explants used in the present study. Trials with various combinations of auxins and cytokinins in the present study have evidenced that MS medium supplemented with $5 \times 10^{-6}$ $\mathrm{M}$ IBA and $10^{-6} \mathrm{M}$ BAP showed maximum $33.9 \%$ callus induction from leaf lamina followed by petioles $(32.7 \%)$, nodal segments $(26.7 \%)$ and cotyledonary nodes $(19.3 \%)$. Callus mediated shoot regeneration was also reported on this media. In favour of this observation, Sujtha and Mukta (1996) have reported callus mediated regeneration on medium supplemented with BAP $(0.22 \mu \mathrm{M})$ and IBA $(0.49 \mu \mathrm{M})$ from leaf disc and hypocotyl explants. They reported that petioles required still lower concentrations of IBA $(0.44 \mu \mathrm{M})$ and BAP $(0.49 \mu \mathrm{M})$. They also suggested that the callus induction was genotype dependent. Similar to this observation, Sardana et al. (2000) also succeeded to establish callus in J. curcus on MS medium supplemented with Gamborg's vitamins $\left(\mathrm{B}_{5}\right)$ and auxins in combination with cytokinin $(3.0 \mathrm{mg} / \mathrm{L}$ each of both IAA and BAP) from leaf explants taken from 5-7 days old seedlings. It is generally known that auxin in high concentrations induces embryogenic callus effectively. The results obtained from the present study, also shown that BAP is essential for inducing embryogenic callus from petioles and nodal segments of $J$. curcas. However, Ramasamy et al. (2005) reported that auxins alone or in combination with cytokinin greatly influences the frequency and also has a significant impact on the induction on 
embryogenic callus induction. Kumari and Jaiwal (1998) found the requirement of cytokinin in addition to auxin essential to induce embryogenic callus in Terminalia arjuna. Similar observation was made for the species Psoralea corylifolia (Sahrawat and Chand, 2001). Unlike the above two reports, we also obtained embryogenic callus from petioles with cytokinins only (Data not shown here). Similar to this observation, there are reports that BAP alone, when added to the basal medium, induced embryogenic callus in Hipperstrum hybridum (Mujib et al., 1998) and Sequoia sempervirens (Liu et al., 2006).

For further optimization of the best growth regulator combination, MS medium supplemented with $5 \times 10^{-6}$ $\mathrm{M}$ each of BAP and KIN was amended with either NAA or IBA $\left(2.5 \times 10^{-6} \mathrm{M}\right)$. Both these combinations, although improved callus growth significantly; medium supplemented with NAA showed an edge over the IBA supplemented medium. Thus, trails with different combinations of auxins and cytokinins, different explants have vividly evidenced that among different explants tried, leaf lamina was the best responding explant and MS medium supplemented with $5 \times 10^{-6} \mathrm{M}$ NAA and $10^{-5} \mathrm{M} 2$, 4-D was the best callusing and growth supporting medium. In the present study, it was also observed that MS media independently or in combination, of the growth regulators can induce callus formation. However, the regenerative competence of the callus tissues can differ depending on the type of explants used because certain types of plant tissues have more favorable regeneration responses than others. Similar results were reported by Kumar and Reddy (2010).

\section{Conclusion}

The present study concluded that leaf lamina had best callus responses among all explants thus tested and MS-13 media supplemented with $5 \times 10^{-6}$ M NAA and $10^{-5} \mathrm{M} 2,4-\mathrm{D}$ was best for in vitro callusing and growth support. However, the regenerative competence of the callus tissues can differ depending on the type of explants used because certain types of plant tissues have more favorable regeneration responses than others. The callus induction rates obtained in this study were highest in comparison of earlier reports. The callus induction protocol thus developed can be used for the improvement of $J$. curcas through biotechnological tools for obtaining agronomically desirable genotypes.

\section{ACKNOWLEDGEMENTS}

The authors are grateful to the Head, Department of Agricultural Biotechnology, S.V.P. University of Agriculture and Technology Meerut, Uttar Pradesh for providing the necessary facilities for conducting this research work.

\section{REFERENCES}

Abdulla, R., Chan, E.S. and Ravindra, P. (2011). Biodiesel production from Jatropha curcas: a critical review.
Critical Reviews in Biotechnology, 31:53-64.

Deore A.C. and Johnson T.S. (2008). High-frequency plant regeneration from leaf-disc cultures of Jatropha curcas L.: an important biodiesel plant. Plant Biotech. Reporter, $2: 10-15$.

Gamborg, O.L., Miller, R.A. and Ojima, K. (1968). Nutrient requirements of suspension cultures of soybean root cells. Exp. Cells Research, 50:151-204.

Jose, J., Nimisha, K., Anu M.A. and Nambisan, P. (2012). Evaluation of somaclonal variation in callus cultures of Jatropha curcas maintained on different hormonal combinations using RAPD markers. World Journal of Agricultural Sciences, 8(6): 616-623.

Kaushik, N. and Kumar, S. (2004). Jatropha curcas L. Silviculture and Uses. Agrobios (India), Jodhpur.

Kumar, A. and Sharma, S. (2008). An evaluation of multipurpose oil seed crop for industrial uses (Jatropha curcas L.): a review. Ind. Crops Prod., 28:1-10.

Kumar, N. and Reddy, M.P. (2010). Plant regeneration through the direct induction of shoot buds from petiole explants of Jatropha curcas: a biofuel plant. Ann. Appl. Biol., 156:367-375.

Kumari, N. and Jaiwal, V.S. (1998). Induction of somatic embryogenesis and plant regeneration from leaf callus of Terminalia arjuna Bedd. Current Science, 75:1052-1055.

Liu, C., Xia, X., Yin, W., Hung, L. and Zhou, J. (2006). Shoot regeneration and somatic embryogenesis from needles of redwood (Sequoia sempervirens). Plant Cell Rep., 25:621-628.

Li, M., Li, H., Jiang, H., Pan, X. and Wu, G. (2007). Establishment of an Agrobacterium-mediated cotyledon disc transformation method for Jatropha curcas. Plant Cell Tiss. Org. Cult., 92:173-181.

Menezes, R.G., Rao, N.G., Karanth, S.S., Kamath, A., Manipady, S. and Pillay, V.V. (2006). J. curcas poisoning. Ind. J. Pediatr., 73:634.

Mujib, A., Bandyopadhyay, S., Jana, B.K. and Ghosh, P.D. (1998). Direct somatic embryogenesis and in vitro plant regeneration in Hippeastrum hybridum. Plant Tissue Cult., 8(1):19-25.

Murashige, T. and Skoog, F. (1962). A revised medium for rapid growth and bioassay with tobacco tissue cultures. Physiol. Plantarum, 15:473-479.

Rajore S. and Batra, A. (2007). Efficient plant regeneration via shoot tip explants in Jatropha curcas. J. Plant Biochem. Biotech., 14, 73-75.

Ramasamy, N., Ugandhar, T., Praveen, M., Venkataiah, P., Rambabu, M., Upender, M. and Subhash, K. (2005). Somatic embryogenesis and plantlet regeneration from cotyledons and leaf explants of Solanum surattense. Indian J. Biotechnology, 4:414-418.

Sahrawat, A.K. and Chand, S. (2001). Continuous somatic embryogenesis and regeneration from hypostyle segments of Psoralea corylifolia Linn: An endangered and medicinally important Fabaceae plant. Current Science, 81:1328-1331.

Shamsiah, A., Awal, A., Nurathrah, S., Khairul-Azmir, M. and Norrizah, J.S. (2010). Effects of BAP concentration on in vitro shoot multiplication and callus induction in Jatropha curcas. In: Proceedings of XXVII International Horticultural Congress on Science and Horticulture for people (IHC-2010)- International symposium on micro and macro technologies for plant propagation and breeding in horticulture, pp. 27-37.

Sardana, J., Batra, A. and Ali, D.J. (2000). An expeditious 
Schekar, R.U. and Hilderbrandt, A.C. (1972). Medium and techniques for induction and growth of monocotyledonous and dicotyledonous plant cell cultures. Can. J. Botany, 50:199-204.

Sridhar, T.M. and Naidu, C.V. (2011). An efficient callus induction and plant regeneration of Solanum nigrum L. - An important antiulcer medicinal plant. Journal of Phytology, 3(5):23-28.

Shrivastava, S. and Banerjee, M. (2008). In vitro clonal propagation of physic nut (Jatropha curcas L.): Influence of additives. Int. J. Integr. Biol., 3:73-79.
Sujatha, M. and Mukta, N. (1996). Morphogenesis and plant regeneration from tissue cultures of Jatropha curcas. Plant Cell Tiss. Org. Cult., 44:135-141.

Thepsamran, N., Thepsithar, C. and Thongpukdee, A. (2008). In vitro induction of shoots and roots from $J$. curcas L. explants. J. of Hort. Science and Biotechnology, 83: 106-112.

Thomas, R., Sah, N.K. and Sharma, P.B. (2008). Therapeutic biology of Jatropha curcas: a mini review. Current Pharm. Biotechnol., 9:315-24. 